\title{
Proposed Estimation Method of Origin-Destination Matrix for Agglomeration
}

\author{
Alexey Levashev \\ Transport Management and Logistics Department \\ Irkutsk National Research Technical University \\ Irkutsk, Russia \\ alexey.levashev@tl-istu.com
}

\author{
Alexander Mikhailov \\ Transport Management and Logistics Department \\ Irkutsk National Research Technical University \\ Irkutsk, Russia
}

\begin{abstract}
The article is to address the problem of developing a transportation model for agglomeration. The approach to designing this model in urban agglomeration through a combination of several transportation demand models is examined. The estimation method for traffic flow distribution between the cities within agglomeration based on travel time is suggested.
\end{abstract}

Keywords - transportation model for agglomeration, origindestination matrix estimation method, transportation corridor, transportation analyzis zone (TAZ)

\section{INTRODUCTION}

Many Russian cities are currently facing the problem of urban sprawl, i.e. suburbanization, which is manifested through spreading to the municipal units which border on cities. Such urbanized areas form an additional transportation demand for the city center of agglomeration. In light of this, it is becoming vital to design a transportation model of agglomerations and further use it for effective decisionmaking on the topic. One of the relevant examples is the city of Irkutsk, which suburban area (Irkutsk District) is expected to amount to approximately 200,000 dwellers by 2030 considering its estimated pace of growth. If achieved, this population would constitute almost one third of the current population of Irkutsk. Thereby, the sound development of the transportation network of the city can no longer be planned without estimating the traffic load of Irkutsk District and the neighboring cities of Angarsk and Shelekhov.

Using cordons is very common in transportation planning for estimating a travel demand arising outside the actual borders of the studied city but still closely connected to it. However, when examining a transportation model of agglomeration this approach cannot provide a comprehensive picture of the development of transportation demand, especially if consideration of its territorial formation is required.

A number of researchers from different countries [1-19] have studied a wide range of challenges in relation to the estimation of traffic conditions and the transportation demand within the borders of individual road networks, and in cities in general. In particular, the authors of this paper researched the demand estimation within an urban transport corridor [4] utilizing modern geo-information source data needed for transportation modeling. At the same time, approaches to the transportation systems modeling of urban agglomerations are not yet thoroughly researched in related literature. At present, only intercity travel demand models are practically implemented in Russia.

\section{METHODS AND MATERIALS}

Development of a transportation model of agglomeration is usually regarded as a territorial expansion of the transportation model of the central city of agglomeration with calculating additional transport zones. Such transportation model development necessitates the calculation of new origindestination (OD) matrix. We believe that there are alternative methods to do that, particularly in case of the agglomeration which can incorporate transport corridors in the form of main highways. We assume that a winning approach is the one that enables one to use OD matrices computed for the individual cities and transport corridors integrated in agglomeration. Estimation of the transportation demand for the traffic flow within agglomeration may be illustrated as a combination of the following:

- Transportation model of an urban kernel of agglomeration and of a satellite town including studying the transport corridor connecting them.

- Transportation model of an urban kernel of agglomeration and of the transport corridor incorporated in the kernel of agglomeration.

In this article, we examine the second case, i.e. calculation of the OD matrix using the two components below:

- Existing transportation model of an urban kernel of agglomeration

- Complementing it with the transportation models of the key corridors within agglomeration.

In order to design the transportation model 'city + corridors', it is suggested to use a combination of transportation demand models, including a separate model of intercity travel demand and of the transportation demand developed for individual transport corridors. 
The general approach to designing a new model that aims to integrate a transportation model of the city with the one of the corridors is presented in Fig. 1. In this particular case, main highways appear as transport corridors.

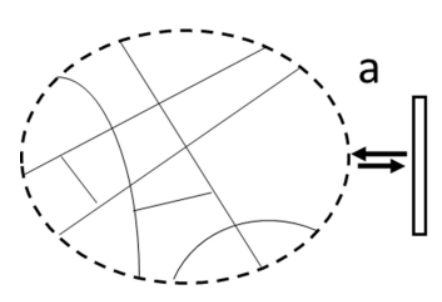

model: city + cordon

b
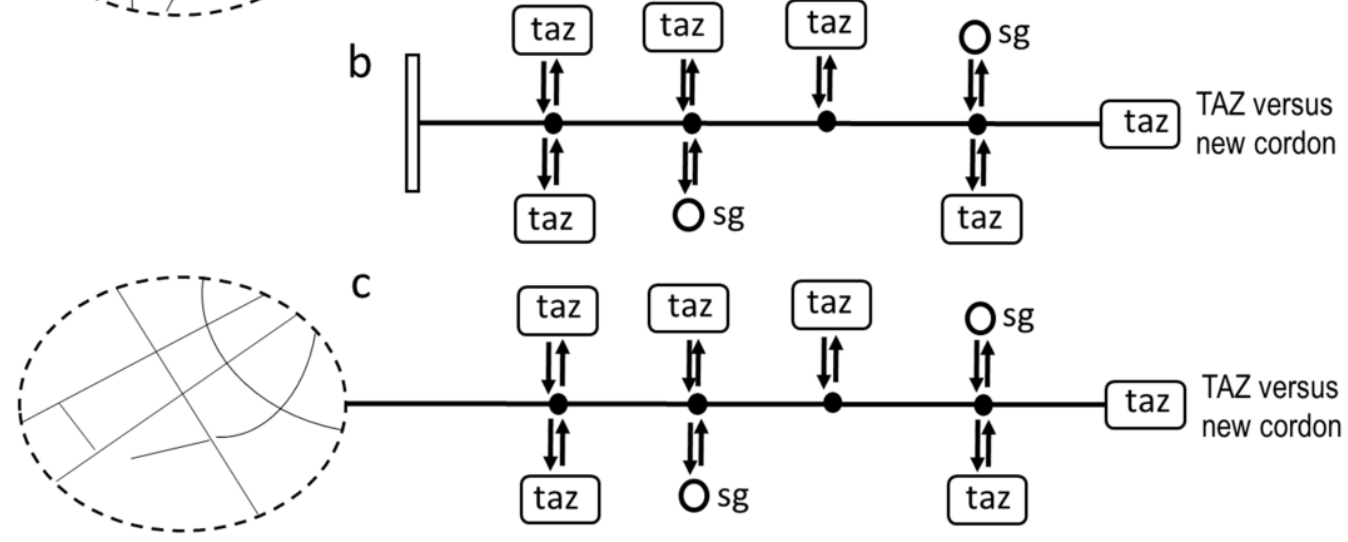

new model: city + corridor

Fig. 1. Integration of the transportation model of the city and transport corridor: a - model of the city, including cordon; $\mathrm{b}$ - model of the corridor, including cordon; $\mathrm{c}$ - integrated model of the city and transport corridor; taz - transportation analysis zones; sg - special generators (shopping centers, megamarkets and etc.)

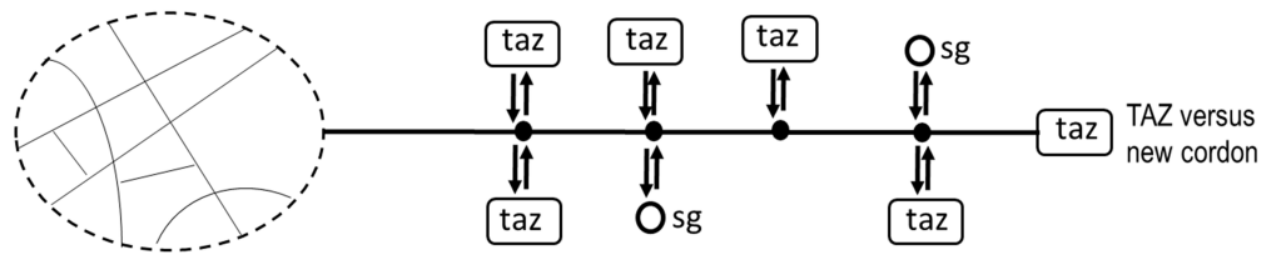

$f(t)$

a)

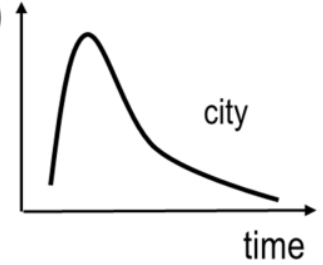

$f(t)$

b)

$f(t)$

t) $\uparrow$

c)

$f(t)$

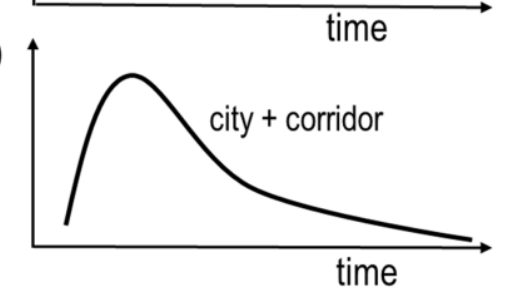

$f(t)$

d)

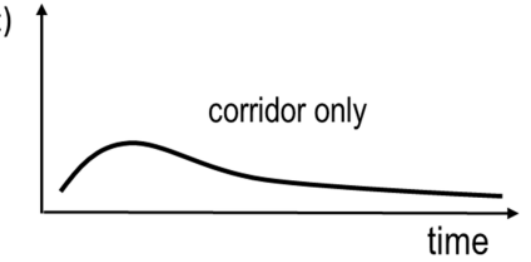

Fig. 2. Travel time distribution (relationship between transit patronage and travel time): $\mathrm{a}$ - within a transportation model of the city; $\mathrm{b}$ - within a model of transport corridor; $\mathrm{c}$ - cordon and transport zones of the corridor; $\mathrm{d}$ - only transport zones of the corridor; $\mathrm{e}$ - both transport zones of the city and of the corridor 


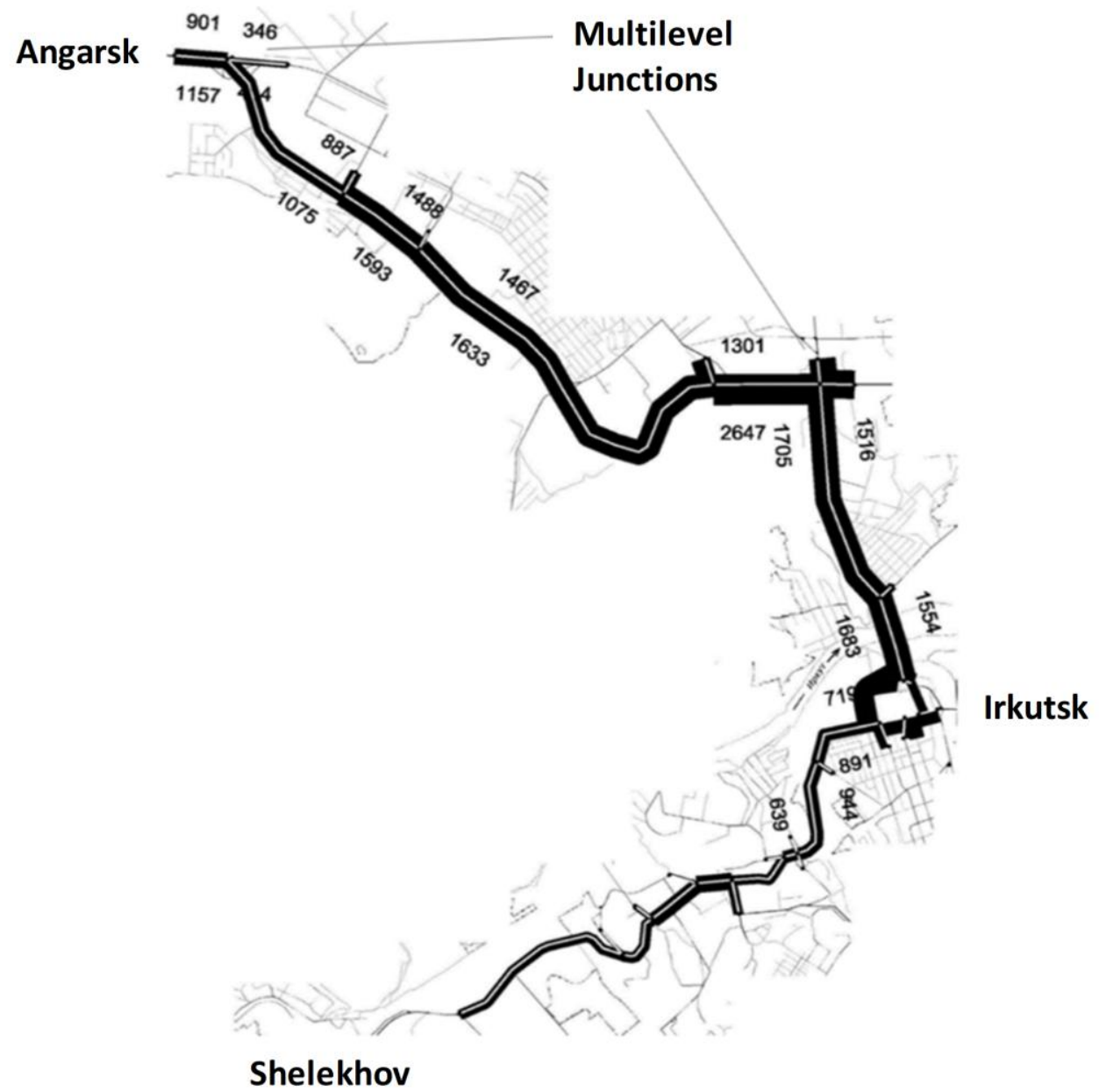

Fig. 3. Transport corridor of Angarsk-Irkutsk-Shelekhov within the Irkutsk agglomeration

When integrating the transportation models of the city and corridor into a new model, a new ratio of the number of vehicles and travel time should be computed. The theoretical representation of the method estimating a corresponding function is demonstrated in Fig. 2.

\section{DISCUSSION}

The first component of the required data to address the task is already incorporated in the transportation model of the city as follows:

- Estimated transportation demand within a city, i.e. computed OD matrix and distribution of traffic flow on the road network.

- External transportation demand is illustrated in the form of a virtual TAZ (i.e. cordon).

The second part relates to the transportation model of the corridor. Computing of this model can be conducted in five sequential steps:
1. Estimation of the existing OD matrix of the transport corridor based on the network measurements representing the corridor.

2. Based on the calculated OD matrix, travel time distribution (relationship between transit patronage and travel time) of the examined corridor is estimated.

3. The OD matrix of the corridor is divided by the OD matrix within the corridor and the OD matrix of TAZ and SG with a cordon(s) (see Fig. 2).

4. The travel time distribution computed for the corridor is divided by the travel time distribution of transportation demand within the corridor and for the demand with a cordon(s) as origin or destination zones (if the corridor ends with a cordon not with TAZ).

5. Trip generation rates are estimated for each TAZ and SG. These data can further be used for forecasting travel demand in case new transport zones and special generators are added. 
New OD matrix between transport zones of the city and the transport corridor itself is calculated through a widely applied gravity model as follows:

$$
x_{i j}=A_{i} B_{j} O_{i} D_{j} f\left(t_{i j}\right)
$$

where $A_{i}$ and $B_{j}$ - balancing factors; $O_{i}-$ number of trips originating in transport zones; $D_{j}-$ number of trips terminating in transport zones; $f\left(t_{i j}\right)$ - function of travel time.

At the same time, the capacity of transport zones in terms of originating $\left(O_{i}\right)$ and terminating $(\mathrm{Dj})$ trips in the new matrix is calculated as the sum of the transportation demand but only where a cordon (city-corridor) was an origin or destination zone, and where the case of e (city - corridor) (Fig. 2) is viewed as the function of future traffic $f\left(t_{i j}\right)$.

By now the solution of the OD matrix reconstruction of a transport corridor has been already found [see 4,5$]$ which is illustrated well with the federal highways M53-M55 leading to Irkutsk (Fig. 3). This corridor stretches for $35 \mathrm{~km}$ and encompasses 24 intersections with two of them at multiple levels. Source data were collected using video recording and registration of plates.

A preliminary experiment aimed to estimate the accuracy of OD matrix reconstruction (see Table 1 below) was carried out using the following methods:

- $\quad$ method TFlowFuzzy (VISUM software);

- minimization of the sum of squared deviations (AIMSUN software);

- robust regression - minimization of the sum of absolute deviations (method suggested by TL-ISTU)

TABLE I CROSS-COMPARISON OF THE METHODS TO MEASURE THE ACCURACY OF OD MATRIX RECONSTRUCTION

\begin{tabular}{|c|c|c|c|}
\hline \multirow{2}{*}{$\begin{array}{c}\text { Statisti } \\
\text { cs }\end{array}$} & \multicolumn{3}{|c|}{ Methods for matrix reconstruction } \\
\cline { 2 - 4 } & VISUM & AIMSUN & TL-ISTU \\
\hline RMSE & 0,6619 & 0,6619 & 0,3907 \\
\hline
\end{tabular}

The experiment with virtual corridors demonstrated higher reliability in the application of robust regression (TL-ISTU method), which was used for the current OD matrix estimation within the studied transport corridor.

In the TL-ISTU method, we obtained dependencies characterizing the effect on the accuracy of transportation demand estimation, its magnitude and distance. The RMSE accuracy index (the ratio of standard deviation to the average value of transportation demand) decreases with the increase of transportation demand. At the same time, RMSE showed the following values: transportation demand less than 50 vehicles per hour equaled to $0.8-1.0$, while it equaled to $0.7-0.8$ in case of 50 to 100 vehicles per hour. The accuracy of transportation demand estimation is defined as a function of distance from the entrance to a considered highway to the examined problem point of the highway. The increase in the fraction of absolute deviation as a distance function is approximated by a nonlinear function, according to which the accuracy of transportation demand is estimated with the following reliability: $95 \%$ - at a distance of up to $7 \mathrm{~km} ; 90 \%$ - at a distance of up to $15 \mathrm{~km} ; 87.5 \%$ - at a distance of up to $25 \mathrm{~km}$.

\section{CONCLUSION}

Overall, the results of the current OD matrix reconstruction showed that transit traffic through the Irkutsk agglomeration in the examined corridor amounts to only $5 \%$.

Other transport corridors of the Irkutsk agglomeration are already examined at the new stage of the research. Moreover, the citizens of Irkutsk, Angarsk and Shelekhov are currently being surveyed, with the aim of defining the relationship between future traffic and travel time both within each municipality and between them. Obtaining a representative sample regarding the travel time will enable one to address the next task, which is the estimation of the OD matrix within Irkutsk, Irkutsk and Shelekhov District and Angarsk Municipal District. This will become a solid ground for developing a transportation model of the agglomeration.

\section{References}

[1] M.G.H Bell, "The estimation of origin-destination matrices by constrained generalised least squares", Transportation Research B, vol. 25B, No.1, pp. 13-22, 1991.

[2] E. Cascetta, S. Nguyen, "A unified framework for estimating or updating origin/destination matrices from traffic counts", Transportation Research 22B, pp. 437-455, 1988.

[3] G. Chang, J. Wu, "Recursive estimation of time-varying origindestination flows from traffic counts in freeway corridors", Transportation Research-B, Vol. 28B, pp. 141-160, 1994.

[4] D. Di, D. Yang, "Dynamic traffic analysis model of multiple passengers for urban public transport corridor", Advances in Mechanical Engineering, Vol. 7(11), p. 1-10, 2015.

[5] J. Teng, X. Lai, "An integrated method for urban transit evaluation and optimization. Advances in Mechanical Engineering”, Vol. 9(7), p. 1-14, 2017.

[6] A. Levashev, "Application of geoinformation technologies in transportation", 12th International conference "Organization and traffic safety management in large cities", SPbOTSIC-2016, St. Petersburg, Russia - Transportation Research Procedia 20 (2017), pp. 406 - 411, 2830 September 2016.

[7] A. Levashev, "Modelling of transport corridors in cities and agglomerations. Modern tendencies of urban system development", Proceedings of the international scientific conference dedicated to the 135th Anniversary of Prof. Babykin K., the founder of Ural School of Architecture. Eds. Postnikov S., Yankovskaya Y., Vityuk E., Ural State Academy of Visual Arts and Architecture, OJSC "Russian Railways" Sverdlovsk Railway, pp. 221-223, 2015.

[8] A. Levashev, A. Mikhailov, I. Golovnykh, "Modeling parking based trips", Proceedings of the VIII-th International Conference on «the Sustainable City VIII», WIT Press, UK, vol. 2., pp. 1067 - 1076, 2013.

[9] A. Levashev, A. Mikhailov, M. Sharov, "Irkutsk transportation master plan solutions to the public transport system development", Proceedings of the international conference on «Energy production and management in the 21 st century - The quest for sustainable energy», WIT Press, UK, vol. 1, pp. $651-660,2014$.

[10] A. Levashev, E. Prelovskaya, "Modern approach of street space design", 12th International conference "Organization and traffic safety management in large cities", SPbOTSIC-2016, St. Petersburg, Russia Transportation Research Procedia 20 (2017), pp. 523 - 528, 28-30 September 2016. 
[11] M. Maher, "Inferences on trip matrices from observations on link volumes: a Bayesian statistical approach", Transportation Research 20B, pp. 435-447, 1983.

[12] A. Mikhailov, A. Levashev, M. Sharov, "Modern quality estimation methods of traffic management in cities", Irkutsk, Manuscript of VINITI, of No. 64-B, pp. 218, 2015.

[13] M. Nawaz, S. Somenahalli, A. Allan, "Bus-based transit-oriented development (BTOD): Opportunities and challenges for low-density, car-dependent Australian cities", Road \& transport research, Vol. 26, p. 62-74, 2017.

[14] E. Prelovskaya, A. Levashev, "Transportation model of the irkutsk agglomeration", LAP LAMBERT Academic Publishing. Saarbrücken, Germany, p. 60, 2014.

[15] M. Sharov, A. Levashev, A. Mikhailov, "The Irkutsk transportation master plan solutions to public transport system development" WIT Transactions on Ecology and the Environment, 190 VOLUME 1, 651$660,2017$.
[16] S. Tebenkov, A. Levashev, "Results of the estimation of traffic streams in transport corridors", Vestnik of ISTU, No.10, pp. 120-127, 2011.

[17] S. Tebenkov, A. Levashev, A. Mikhailov, "Analysis of traffic streams in transport corridors", Problems and perspectives of the development of Euroasian transportation systems: Proceedings of the 2nd International scientific and applied conference, 11 May 2010, Chelyabinsk, Russia Publishing center of SUSU, pp. 213-218, 2010.

[18] N.J. Van Der Zijpp, R. Hamerslag, “An improved Kalman filtering approach to estimate origin-destination matrices for freeway corridors", Transportation Research Records, No.1443, pp. 54-64,1994.

[19] A. Vulevic, D. Macura, D. Djordjevic, R. A. Castanho, “Assessing accessibility and transport infrastructure inequities in administrative units in Serbia's Danube corridor based on multi-criteria analysis and GIS mapping tools", Transylvanian Review of Administrative Sciences, pp. 123-143, 2018. 